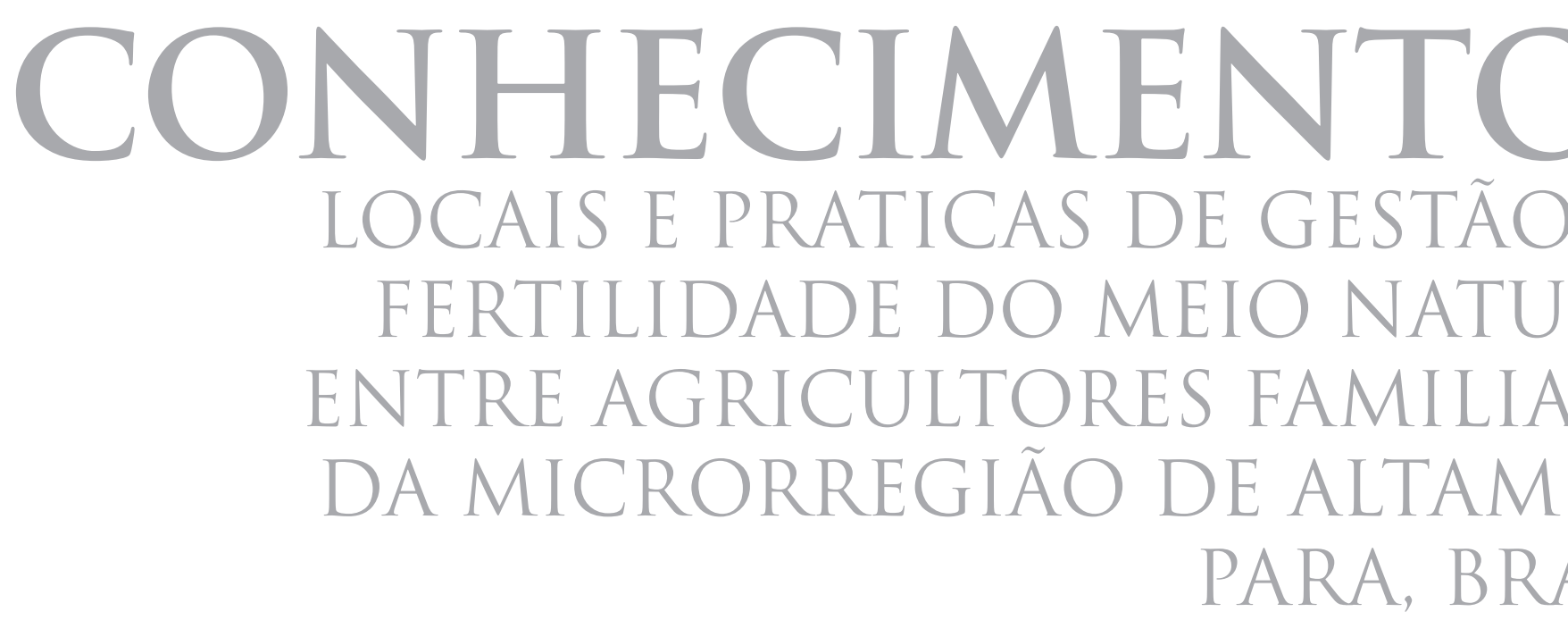




\section{CONHECIMENTOS}

LOCAIS E PRATICAS DE GESTÃO DA FERTILIDADE DO MEIO NATURAL ENTRE AGRICULTORES FAMILIARES DA MICRORREGIÃO DE ALTAMIRA,

PARA, BRASIL

\section{CARLA GIOVANA SOUZA ROCHA} Universidade federal do pará, brasil J A L CIONE PEREIRA DE A LMEIDA UNIVERSIDADE FEDERAL DO RIO GRANDE DO SUL, BRASIL 


\title{
CONHECIMENTOS LOCAIS E PRATICAS DE GESTÃO DA FERTILIDADE DO MEIO NATURAL ENTRE AGRICULTORES FAMILIARES DA MICRORREGIÃO DE ALTAMIRA, PARA, BRASIL
}

\section{Resumo}

Busca-se identificar e analisar as práticas socioprodutivas de agricultores familiares na microrregião de Altamira, Pará, em relação aos conhecimentos sobre o meio natural, suas limitações e potencialidades naturais. Foram feitas entrevistas semiestruturadas com mediadores locais e com 60 famílias em três localidades rurais nos municípios de Brasil Novo, Medicilândia e Pacajá. Além disso, realizou-se conversas informais e observação em percursos nos estabelecimentos agrícolas. Nas percepções dos agricultores sobre as transformações na natureza, notou-se a relação com o processo de desmatamento e as consequências negativas percebidas em seus próprios sistemas familiares de produção. Os conhecimentos sobre a gestão da fertilidade foram adquiridos na prática, em um processo de aprendizagem individual e coletiva, de experimentação, da percepção dos riscos impostos por fatores biofísicos e de produção. Os conhecimentos locais dos agricultores sobre as restrições e potencialidades do meio natural para suas atividades produtivas são a base para a tomada de decisão no que concerne às práticas de gestão de seus elementos, assim como a perspectiva das famílias de assegurar ou não a reprodutibilidade do sistema em longo prazo.

Palavras-chave: Relação sociedade-natureza, reprodução social, transamazônica.

\section{LOCAL KNOWLEDGES AND PRACTICES OF MANAGEMENT OF FERTILITY OF NATURAL ENVIRONMENT BETWEEN FAMILY FARMERS IN MICROREGION ALTAMIRA, PARA, BRAZIL}

\begin{abstract}
Objective is to identify and analyze the socioproductives practices of family farmers in the microregion of Altamira in relation at local knowledge about the natural environment, its limitations and natural potentialities. Semi-structured interviews were conducted with local mediators and with 60 families of three rural localities in the municipalities of Brasil Novo, Medicilândia and Pacajá, in addition to informal conversations and courses in agricultural establishments. In the perceptions of farmers about the transformations in nature were emphasized the relationship with the process of deforestation and the negative consequences perceived in their own family systems of production. The knowledge about the management of fertility were acquired in practice, in a process of individual and collective learning, experimentation and the perception of risks imposed by biophysical factors and production. The local knowledge of farmers on the constraints and potential of the natural environment for their productive activities are the basis for the decisionmaking on the management practices of its elements, as well as, the presence
\end{abstract}


of the perspectives to ensure or not the reproducibility of the system in the long term.

Keywords: Society-nature relationship, social reproduction, transamazon highway.

\section{CONOCIMIENTOS LOCALES Y PRÁCTICAS DE GESTIÓN DE LA FERTILIDAD DEL MEDIO NATURAL DE PRODUCTORES FAMILIARES EN LA MICRORREGIÓN ALTAMIRA, PARA, BRASIL}

\section{Resumen}

Trata de identificar y analizar las prácticas socioproductivas de los agricultores familiares en la microregión de Altamira en relación con los conocimientos sobre el medio natural, sus limitaciones y potencial natural. Se llevaron a cabo entrevistas semiestructuradas con mediadores locales y con 60 familias de tres localidades rurales de los municipios de Brasil Novo, Medicilândia y Pacajá, además de conversaciones informales y cursos en establecimientos agropecuarios. En las visiones de los agricultores acerca de las transformaciones en la naturaleza se hizo hincapié en la relación con los procesos de deforestación y los impactos negativos percibidos en sus propios sistemas familiares de producción. El conocimiento en el manejo de la fertilidad fueron adquiridos en la práctica, en un proceso de aprendizaje personal y colectivo, la experimentación y la percepción de los riesgos impuestos por factores biofísicos y la producción. El conocimiento local de los agricultores sobre las limitaciones y posibilidades del medio natural, por sus actividades productivas son la base para la toma de decisiones sobre las prácticas de gestión de sus elementos, así como, la presencia de la perspectiva de las familias para garantizar la reproducibilidad o no del sistema a largo plazo.

Palabras-clave: Relación sociedad-naturaleza, reproducción social, Transamazónica.

Endereço da primeira autora para correspondência: NCADR- Universidade Federal do Pará, Rua Augusto Corrêa, No 1, Cidade Universitária José da Silveira Neto, Guamá, CEP 66075-110, Belém, PA, Brasil. E-mail: crocha@ufpa.br 


\section{INTRODUÇÃO}

Uma das ideias centrais da Etnoconservação e da Etnoecologia é a consideração de que os saberes locais são fundamentais para manter e aumentar a variedade genética, os policultivos, a diversidade das práticas produtivas e a heterogeneidade paisagística, que contribuem para manter a sustentabilidade dos agroecossistemas, isso baseado na capacidade de resiliência dos sistemas (Toledo 2005). Parte-se do pressuposto de que existem racionalidades ambientais e ecológicas de populações tradicionais que favorecem o uso conservacionista ou não destrutivo dos elementos naturais (Leff 2009).

A sistematização e compreensão destas racionalidades e conhecimentos das populações tradicionais são vistos como instrumento fundamental para contraposição aos modelos produtivistas. A perspectiva final é a busca de uma nova racionalidade produtiva, em que haja vinculação da conservação da biodiversidade ao respeito pela heterogeneidade étnica e cultural (Leff 2009). A construção e a adoção de sistemas, assim como práticas agrícolas que visem à conservação ambiental e à melhoria de vida da população rural e urbana, são demandadas por uma parcela da sociedade e instituições críticas aos padrões de produção e de consumo agrícola modernos.

Assim, destaca-se a importância das culturas tradicionais para o desenho de sistemas agrícolas alternativos, ecologicamente relevantes, cujo intuito é a conservação dos elementos bióticos e genéticos usados como base aos novos estilos de desenvolvimento rural (Toledo 1990).
Toledo (2005) utiliza o termo "saber local" para se referir a toda uma gama de conhecimentos de caráter empírico transmitidos oralmente e que são próprios das formas não industriais de apropriação da natureza. Este autor argumenta que o agricultor tradicional possui um detalhado catálogo de conhecimentos acerca da estrutura dos elementos da natureza, sobre as relações que se estabelecem entre eles, os processos ou dinâmicas e seu potencial utilitário, o que se aplicaria também aos fenômenos de caráter astronômico, físico, biológico e ecogeográfico. Barrera-Bassols \& Toledo (2005) destacam a existência de quatro tipos de conhecimentos locais: estrutural, relacional, dinâmico e utilitário.

Os conhecimentos sobre os solos, clima, vegetação e dos animais, em seu caráter morfológico e dinâmico, influenciam as decisões familiares na escolha do local para plantar, o que plantar e quando plantar ou realizar qualquer operação nos cultivos e nas criações. A percepção da situação do meio natural, assim como de sua capacidade de renovação está enraizada neste conhecimento construído por meio da prática e das informações acessadas e mobilizadas, conformando a experiência individual e a transmissão para as futuras gerações.

Toledo (2005) destaca o exemplo de sistemas de classificação dos solos de caráter multi-hierárquico, baseados fundamentalmente nas características morfológicas, as quais são ao mesmo tempo dinâmicas, utilitárias e simbólicas. Pode-se também citar o sistema de conhecimento relacionado à dinâmica 
da vegetação secundária e das pastagens, onde existe uma diferenciação feita pelos agricultores de cada etapa de regeneração da vegetação e do tempo de pousio necessário para que a parcela possa ser novamente utilizada para plantio. $\mathrm{O}$ porte e densidade da vegetação secundária são indicativos da quantidade de nutrientes que será disponibilizada às plantas pela queima da biomassa e a quantidade de tempo de trabalho a ser poupado com o controle das plantas espontâneas.

Veiga \& Albaladejo (2002) e Tavares \& Veiga (2006) analisam as relações entre os saberes técnicos, a percepção do meio natural e a diversidade das práticas agrícolas, e enfatizam a importância das relações sociais estabelecidas entre os agricultores, reconhecendo as diferenciações dadas pela diversidade social e pelas percepções da heterogeneidade do meio natural de um determinado local. Robert (2000, citado por Tavares \& Veiga 2006) indica que para identificar as lógicas locais de gestão do meio nos discursos dos agricultores faz-se necessário conhecer os critérios que os mesmos utilizam para classificar e qualificar os elementos do meio natural e suas maneiras de pensar e de perceber o meio; para avaliar e classificar os resultados das suas ações técnicas e os critérios para fazer as escolhas nos seus sistemas produtivos.

Este estudo, apresentado parcialmente neste artigo, foi focado na região das estradas, ou seja, onde a ocupação por não indígenas foi iniciada com a abertura da rodovia Transamazônica pelo governo militar na década de 1970.
Trata-se de agricultores familiares migrantes de outras regiões do país, a maioria não se enquadrando como "populações tradicionais" ou locais desta região, mas que ao se depararem com as especificidades do meio natural amazônico, foram induzidos a construir seus referenciais técnicos locais pelo processo de aprendizagem individual e coletiva. Neste artigo será adotado o termo "conhecimento local" de acordo com a conceituação de saber local apontada acima por Toledo.

Visa-se responder à questão de como os conhecimentos sobre o meio natural, das limitações naturais influenciam ou mesmo definem as práticas socioprodutivas de agricultores familiares na microrregião de Altamira, mais precisamente na região de ocupação da rodovia Transamazônica e vicinais. $\mathrm{O}$ objetivo geral do estudo é identificar e analisar as práticas socioprodutivas de agricultores familiares na microrregião de Altamira em suas inter-relações com os conhecimentos sobre o meio natural, limitações e potencialidades naturais. Os objetivos específicos são apresentar as percepções dos agricultores sobre as mudanças na natureza; e, analisar as práticas de gestão dos elementos do meio natural e conhecimentos envolvidos.

Para tanto, as práticas que visam à gestão da fertilidade do meio e do espaço são focadas com maior destaque, o que inclui as práticas de preparo das áreas e os conhecimentos que conduzem às escolhas de terreno para cultivo e das espécies a serem plantadas. Serão também apresentadas as percepções 
dos agricultores sobre as transformações na natureza e a relação com a atividade agrícola, buscando identificar suas preocupações ambientais.

As práticas agrícolas são entendidas como as formas de fazer dos agricultores, as formas como estes ajustam suas técnicas às condições particulares do meio natural e do contexto social. Essas práticas são estudadas levando em consideração as condições nas quais agem os agricultores, analisando o contexto social, econômico e ecológico da ação (Almeida 2000). Portanto, as práticas de gestão dos elementos do meio natural e da fertilidade oferecem bons elementos para analisar as relações de coprodução entre sociedade e natureza.

Reboul $^{1}$ (1989, citado por Veiga 2002) reforça a ideia de que a fertilidade do meio natural é produto da natureza transformada pela prática dos agricultores, sendo o solo (o terreno ou a parcela) um produto socionatural. Desta forma, trata-se da capacidade produtiva do meio como processo construido, coproduzido (entre natureza e sociedade) e não como um objeto dado e imutável (somente natureza). Um determinado tipo de solo ou vegetação, que para alguns agricultores não teria qualidade suficiente para realizar plantios permanentes, para outros é possível cultivá-lo por meio de suas práticas.

Com a noção de fertilidade do meio (natural), busca-se ampliar o conceito agronômico clássico de fertilidade do solo, considerando a fertilidade como algo que não se restringe à potencialidade do solo e a sua capacidade de disponibilizar nutrientes e água aos cultivos. Salienta-se também que a noção de fertilidade do meio, empregada neste estudo não se restringe a sua capacidade de produção, dependendo apenas das funções produtivas atribuídas a este meio e das técnicas mobilizadas para transformálo e de seu custo de realização (Hocdé \& Triomphe 2002).

$\mathrm{Na}$ situação específica a ser estudada, a fertilidade do meio não é função apenas do solo e suas características químicas e físicas, mas da disponibilidade e qualidade da vegetação para ser utilizada no sistema de corte e queima, da quantidade e qualidade da incidência de plantas espontâneas, da atividade da micro e macrofauna do solo e da quantidade de liteira, ${ }^{2}$ considerando também as transformações realizadas por meio das práticas dos agricultores.

\section{PROCEDIMENTOS METODOLÓGICOS}

Este estudo foi realizado no entorno da rodovia Transamazônica, na microrregião de Altamira, no estado do Pará, na área constituída pelos municípios de Altamira, Vitória do Xingu, Senador José Porfírio, Anapu, Pacajá, Brasil Novo, Medicilândia e Uruará, tendo como referência a própria rodovia federal e a bacia do Rio Xingu. O município de Altamira está localizado às margens do Rio Xingu e há 900 km da capital do estado. A Figura 1 identifica os municípios de Brasil Novo, Medicilândia e Pacajá, nos quais estão localizadas as três localidades selecionadas.

As três localidades foram escolhidas tendo como preocupação representar a 


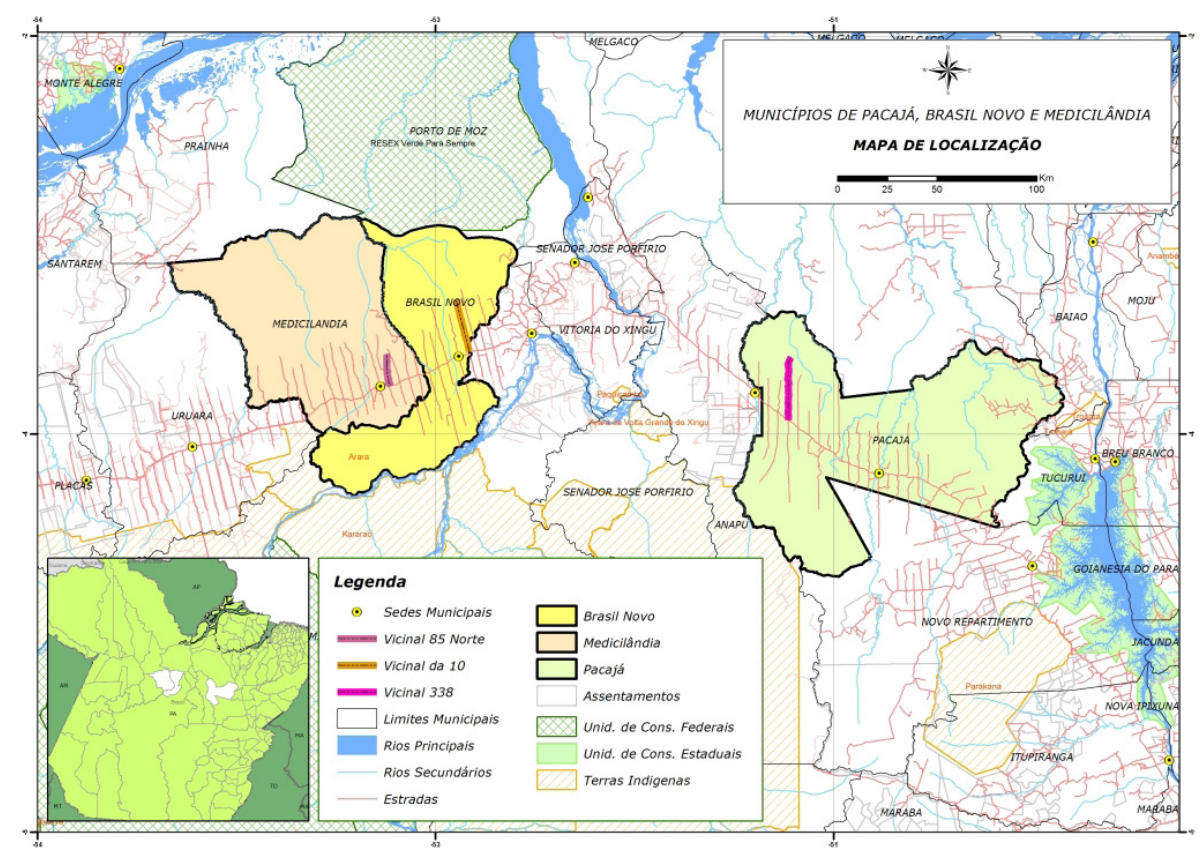

Figura 1 - Localização das áreas de estudo nos municípios de Pacajá, Brasil Novo e Medicilândia, estado do Pará. Fonte: Laboratório de Sensoriamento Remoto/Fundação Viver, Produzir, Preservar (Rocha 2013).

heterogeneidade do meio natural e dos processos de ocupação desta microrregião. Portanto, em cada vicinal foram entrevistadas famílias que chegaram em diferentes épocas de ocupação: a colonização oficial da década de 1970, a ocupação espontânea característica das décadas de 1980 e 1990 e a ocupação com regularização via projeto de assentamento nas décadas mais recentes. No Quadro 1, são destacadas as principais características de cada localidade selecionada.

Foram entrevistadas 60 famílias, cuja escolha foi guiada pelo interesse de se evidenciar casos ilustrativos da heterogeneidade do meio natural e da diversidade social observadas no conjunto das famílias da região estudada. Den- tre os critérios, têm-se: tipos de atividades predominantes nos sistemas de produção e nível de renda (cacau, pecuária bovina de leite ou de corte), lavoura branca (arroz, feijão e milho), qualidade dos solos, disponibilidade de floresta, ciclo familiar, tempo de moradia no estabelecimento agrícola pela identificação de familias recentemente instaladas e de famílias pioneiras de cada época de ocupação.

\section{PERCEPÇÕES DOS AGRICULTORES: AS MUDANÇAS NA NATUREZA E A RELAÇÃO COM O DESMATAMENTO}

Nas entrevistas realizadas no trabalho de campo, verificou-se que o termo "(meio) ambiente" era de difícil compreensão, 
Quadro 1.

Dados gerais sobre as localidades escolhidas para realização do estudo.

\begin{tabular}{|c|c|c|c|}
\hline Localidade & Município & Localização & Principais épocas de ocupação \\
\hline $\begin{array}{l}\text { Vicinal da } \\
\text { Dez }\end{array}$ & Brasil Novo & $\begin{array}{l}\text { Fica a } 12 \mathrm{~km} \\
\text { da cidade de } \\
\text { Brasil Novo } \\
\text { e } 30 \mathrm{~km} \mathrm{da} \\
\text { cidade de Al- } \\
\text { tamira. Possui } \\
\text { mais de } 60 \mathrm{~km} \\
\text { de extensão. }\end{array}$ & $\begin{array}{l}1971 \text { - área de colonização oficial } \\
\text { (até } 12 \mathrm{~km} \text { ). } \\
\text { Década de } 1980 \text { - ocupação das } \\
\text { glebas de } 3000 \text { hectares concedidas } \\
\text { a empresários na década de } 1970 \text { e } \\
\text { que estavam sem uso. O Projeto de } \\
\text { Assentamento Penetecaua somente } \\
\text { foi criado em } 1998 \text {. } \\
1998 \text { - ocupação no último trecho } \\
\text { - mais de } 50 \text { km; no início houve } \\
\text { forte atividade madeireira. }\end{array}$ \\
\hline 338 Norte & Pacajá & $\begin{array}{l}\text { Fica a } 25 \mathrm{~km} \\
\text { da cidade de } \\
\text { Anapu, } 60 \mathrm{~km} \\
\text { da cidade de } \\
\text { Pacajá e } 160 \\
\text { km da cidade } \\
\text { de Altamira. } \\
\text { Possui cerca } \\
\text { de } 50 \mathrm{~km} \text { de } \\
\text { extensão. }\end{array}$ & $\begin{array}{l}1973 \text { - colonização oficial até } 8 \text { km. } \\
1979 \text { - ocupação das glebas (criação } \\
\text { do Projeto de Assentamento Bom } \\
\text { Jardim em 1997). } \\
2000 \text { - ocupação mais recente de } 30 \\
\text { km da faixa; ainda tem presença de } \\
\text { atividade madeireira. }\end{array}$ \\
\hline 85 Norte & Medicilândia & $\begin{array}{l}\text { Fica a } 5 \mathrm{~km} \\
\text { da cidade de } \\
\text { Medicilândia, } \\
85 \mathrm{~km} \text { da } \\
\text { cidade de } \\
\text { Altamira. } \\
\text { Possui } 45 \mathrm{~km} \\
\text { de extensão; } \\
\text { a estrada } \\
\text { encontra-se } \\
\text { com outros } \\
\text { ramais. }\end{array}$ & $\begin{array}{l}1973 \text { - colonização oficial até } 9 \text { km; } \\
1978 \text { - ocupação das áreas a partir } \\
\text { da agrovila; } \\
1981 \text { - ocupação das glebas após } \\
\text { km } 30 \text { (criação do Projeto de As- } \\
\text { sentamento Surubim em 1988). }\end{array}$ \\
\hline
\end{tabular}

Fonte: Rocha (2013).

geralmente necessitando de maiores explicações por parte dos pesquisadores quando incluído em perguntas ou questionamentos aos entrevistados. Para alguns, o termo era imediatamente relacionado ao Instituto Brasileiro do
Meio Ambiente e Recursos Naturais Renováveis (IBAMA), identificado como o "pessoal do meio ambiente". Outra expressão utilizada, que indica o quanto o termo é exógeno, é: “depois dessa história de meio ambiente". 
Ao contrário, o termo natureza geralmente remetia a questões ligadas à proteção dos igarapés e nascentes, às florestas, aos animais silvestres e ao clima (chuvas e temperatura). E, muitas vezes, nessas representações de natureza destacavam-se as alterações ao longo das últimas décadas, geralmente identificadas como consequência do desmatamento.

Em relação a isso, citou-se que a mudança está, sobretudo, na erosão em áreas acidentadas, no assoreamento dos leitos de rios e igarapés, na diminuição dos animais silvestres e no "ataque" destes aos cultivos, na diminuição do volume de água para consumo familiar e para as criações, no aumento da temperatura ou da sensação térmica e menor intensidade das chuvas e alteração na periodicidade das mesmas.

Apesar de estabelecerem a relação entre desmatamento e suas consequências para a natureza e para eles próprios, a maioria dos entrevistados omite o agente e as práticas que levaram a esta situação. Para alguns, os problemas são causados pelos desmatamentos geralmente atribuídos aos grandes fazendeiros. Já quando se interroga sobre a responsabilidade dos agricultores familiares, as justificativas apontadas foram a falta de informação e o incentivo do Instituto Nacional de Colonização e Reforma Agrária (INCRA) para realizar benfeitorias na propriedade, que levariam ao estado atual de desmatamento. Foi também citado que o não cumprimento das leis ambientais e os erros nas práticas devido à falta de conhecimento causaram o assorea- mento de igarapés, justificando-se que "se fazia, às vezes, acompanhando os outros":

Já passei do limite, foi desobediência, eu fiz porque nos governos passados não tinha essa exigência, existia a lei, mas o INCRA colocou coisa errada: quem beneficiasse o lote tinha direito de mais 500 hectares. Tinha essa lei de $20 \%$, mas eu não entendia, entrava e saía pelo ouvido, entendia era de produzir para o consumo e venda. Achava bonito era colocar roça grande, muita fartura. Agora vejo que fiz muita coisa que não devia fazer, me sinto culpado por não ter madeira. Os bichos passando fome e hoje estão me perseguindo na roça (Sr. E., agricultor pioneiro, Medicilândia).

Também há a constatação, por parte dos agricultores, de que o aumento do desmatamento trouxe como consequência a intensidade da estiagem e chegada mais tardia das chuvas no período de inverno, assim vinculando a diminuição do desmatamento a algo positivo, já que a oscilação do calendário de chuvas ocasiona a necessidade de readequação constante aos imprevistos e riscos.

Para os entrevistados com forte ligação às doutrinas religiosas, foi destacado que as mudanças nas chuvas e na sensação de calor são decorrentes da destruição ambiental e que as mudanças climáticas são sinais do "fim dos tempos", conforme a imagem do apocalipse:

As chuvas diminuíram e faz mais calor: são os tempos de Deus. Está escrito que o século será terminado com fogo (...) Os homens [dos órgãos ambientais] estão certos, Deus criou e 
deu ao homem administrar. Está na biblia! A gente precisa de mata; é bom deixar para os filhos. (Sr. P., agricultor, dirigente da Assembleia de Deus, Vicinal 338 N, Pacajá).

A despeito dos inúmeros relatos sobre os problemas ambientais causados pelo desmatamento, quando se pergunta sobre a importância da conservação da floresta remanescente, as famílias mostram preocupação quanto à utilidade do "recurso" e a tendência de escassez do mesmo, principalmente a madeira, expressando o interesse pela aquisição de crédito para reflorestamento.

Na maioria dos relatos dos entrevistados, nota-se que eles ressaltam a importância de se preservar a natureza devido aos benefícios pelo seu uso direto como a extração de madeira, produção de alimentos, utilização da água, de cipós e pelo uso indireto, como fornecedora de sombra, ventilação etc. As mudanças na natureza, incluindo a degradação ambiental, são percebidas quando estas impactam a vida humana. Apesar de serem constatações $a$ posteriori, nos discursos são feitas correlações entre as mudanças no clima e nos elementos do meio natural, assim como as transformações provocadas pelas atividades agrícolas.

$\mathrm{Na}$ busca de reverter processos de degradação ou aumentar a área reflorestada, são abandonadas parcelas de pastagem, de cultivos permanentes e não utilizadas as margens de igarapés para que ocorra a regeneração natural (formação da vegetação secundária). Estas parcelas regeneradas podem ser reincorporadas ao sistema agrícola (sistema de pousio) ou ficar como reserva e reduzir o passivo ambien- tal do estabelecimento agrícola. Também, verificou-se o interesse em manter áreas de vegetação secundária e floresta com o objetivo de preservação e proteção das águas e para o usufruto dos seus sucessores familiares, no entanto, trata-se de manifestações minoritárias.

Nas representações de natureza são enfatizados os elementos naturais diretamente utilizados pelos agricultores para produção ou consumo, assim como os elementos climáticos que interferem na vida rural e na produção agrícola. A noção de coprodução se mostra adequada ao debate teórico, mas os agricultores não visualizam este processo enquanto interdependência entre ser humano e natureza, reduzindo a natureza ao meio biofísico a ser explorado e transformado por meio das práticas e do conhecimento. A natureza, vista como objeto, está subordinada aos interesses e usufruto do ser humano.

Assim, a visão predominante é uma natureza como "recurso", algo a ser explorado, transformado, ainda que esgotável, mas que sua degradação pode ser revertida (ou controlada) pelo uso das técnicas. A técnica é vista como possibilidade de reversão da degradação ambiental, seja ela uma dinâmica que a própria natureza conduzirá como a regeneração natural de uma vegetação ou como recomposição da capacidade de produção de solos pela mecanização agrícola, adubação e irrigação.

Esta visão utilitarista, que pressupõe o controle da natureza pelo ser humano, é coerente com os pressupostos dominantes da modernidade. Há contradições entre os discursos que mostram preocupação com a degradação ambiental e as 
práticas produtivas adotadas pela maioria dos agricultores, em que a natureza é ao mesmo tempo um "recurso" a ser explorado, mas também é um ambiente a ser protegido para o bem-estar da própria população rural.

\section{PRÁTICAS DE GESTÃO DOS ELEMENTOS DO MEIO NATURAL E CONHECIMENTOS LOCAIS ENVOLVIDOS}

As trajetórias das famílias da região evidenciam os principais fatores que influenciam nas decisões produtivas dos agricultores da região da Transamazônica: as percepscoes sobre a qualidade dos solos; as políticas públicas de crédito, de infraestrutura social, estradas e previdência social; a oscilação dos preços e oportunidades de mercado; e o conhecimento técnico.

Os sistemas de produção predominantes na região podem ser resumidos em três grandes grupos: os que obtêm a sustentação econômica na criação de gado bovino, sendo que alguns estão buscando a comercialização do leite, queijo ou massa de queijo de acordo com as oportunidades comerciais locais; o grupo que consegue combinar a criação bovina e os plantios permanentes, notadamente o cacau; e, o grupo que está se especializando no cacau. O cultivo de arroz está em queda devido à restrição do uso de floresta, mas os cultivos de milho, feijão e mandioca permanecem na maioria dos sistemas de produção, apesar da diminuição da área plantada. A tendência é a diminuição da diversificação produtiva.

A escolha pelos agricultores do terreno para plantar segue a tática de se fazer as aberturas na floresta da frente para o fundo do lote, estabelecendo a residência sempre que possível próxima da estrada e da fonte de água potável, ocupando a terra com pastagem desde a frente do lote.

Quando ocorre a escolha criteriosa da área para plantar, as familias utilizam os conhecimentos e experiência adquiridos, principalmente, sobre as características dos solos (textura, cor e presença de impedimentos físicos), o tipo da vegetação antecedente e o relevo. No Quadro 2, são explicitados alguns destes conhecimentos associados à escolha das áreas para cultivo. A percepção da fertilidade do solo, conformada pela experiência individual e coletiva, agrega-se a outros fatores ligados à vegetação original da área escolhida, ao tipo de relevo (baixio, encosta, chapada, plano) e outros.

A citação a seguir faz referência a alguns critérios inseridos no Quadro 2 e retrata como as decisões ligadas ao que produzir e onde instalar as parcelas cultivadas têm forte ligação com a vegetação antecedente, principalmente em localidades com pouca diferenciação nos tipos de solos:

Se queimar bem queimado dá para plantar arroz, mas se sapecar dá para colocar só milho. Se for mata, o milho não dá bem no primeiro ano. $\mathrm{O}$ milho dá bem na juquira. ${ }^{3} \mathrm{O}$ capim do plano fica melhor, nos altos o adubo é fraco, a chuva carrega. (Sr. F. G., agricultor, Brasil Novo).

A escolha da área a ser preparada para plantio segue primeiramente o critério do tipo de vegetação original e a quantidade de biomassa para a queima. A escolha pelo tipo de solo e relevo torna-se um 
critério importante quando se objetiva o plantio de cultivos permanentes, para os quais a fertilidade natural, a capacidade de retenção de água e a ausência de impedimentos físicos são decisivas ao bom desenvolvimento e produção das plantas. Para o plantio de cacau, escolhe-se o tipo de solo mais argiloso e de cor avermelhada, localizado em encostas e nas áreas mais baixas, que retém maior umidade no verão. Geralmente, as famílias identificam todos os solos avermelhados como de terra roxa. Já o capim pode ser plantado em qualquer tipo de solo, como enfatiza a seguir um agricultor entrevistado:

Não se escolhe terra para capim. Fui fazendo as aberturas da frente para o fundo do lote, mantendo o pasto perto de casa. Deveria ter deixado o pasto para trás, mas a prioridade era formar bem o capim, mesmo se prejudicasse o arroz com o consórcio. Como não tinha gado, o capim ficava prejudicado. Plantei cacau na terra com mais barro e mais brejado. O cacau que sai não é o de primeira e no verão sente demais, tem que replantar e manter sempre um viveiro de mudas. (Sr. A. G., agricultor pioneiro, Pacajá).

Observa-se que, no entendimento dos agricultores, o capim pode ser plantado em qualquer tipo de solo, não havendo planejamento mais criterioso quanto à localização da pastagem. Mais recentemente, as famílias já refletem sobre a inadequação do plantio de capim nas margens dos igarapés e nascentes, assim como nas encostas mais íngremes, dadas à erosão, assoreamento e degradação observados na pastagem:
Antes, eu metia motosserra para abrir e não queria saber nem o que ia produzir. Hoje, não abriria nas terras enladeiradas, só estraguei o meio ambiente. Não quero mais abrir em terra enladeirada, o capim se acaba, o gado não aproveita o capim, não pode mecanizar; andar de cavalo nas ladeiras é um perigo. (Sr. R. N., agricultor, Brasil Novo).

A presença na vegetação primária de algumas espécies como o maxarimbé (Cenostigma macrophyllum Tul.) e acapu (Voucapoua americana Ducke) é indicadora de boa fertilidade do solo para os agricultores:

Eu olho se a terra é mista [mistura de trechos com textura argilosa e outros arenosa], amarelada ou roxa, se tem sinal de terreno fértil como bosta de minhoca. Olho o tipo de vegetação, se tiver a presença de maxarimbé e acapu, é sinal de terra boa. (Sr. M., agricultor produzindo cacau orgânico e agente de saúde, Pacajá).

No Quadro 2, na coluna dos “outros critérios" para escolha do terreno, destacase a relação com os animais silvestres, entendidos pelos agricultores como empecilhos ou até como "praga". Os plantios mais nos fundos dos lotes, devido à proximidade da floresta, são mais frequentados pelos animais silvestres que comem os frutos e raízes ou quebram as plantas, por isto muitas famílias evitam realizar plantios nessas áreas. A perda de produção devido à entrada de animais silvestres nas parcelas cultivadas é muito destacada pelas famílias, porém, poucas explicitam a diminuição da área de floresta como a causa dos ataques dos animais aos cultivos. Com isto, tendem a evitar os 


\section{Quadro 2.}

Conhecimentos locais para escolha da área para cultivo na região da Transamazônica, Altamira/PA.

\begin{tabular}{|c|c|c|c|}
\hline Solos & Vegetação & Relevo & Outros \\
\hline $\begin{array}{l}\text { Terra roxa é adequada } \\
\text { para plantio de cacau } \\
\text { e feijão do sul. } \\
\text { Barro amarelo é duro, } \\
\text { resseca; não segura a } \\
\text { água; as plantas não } \\
\text { se desenvolvem (ca- } \\
\text { cau morre no verão; } \\
\text { raízes pequenas de } \\
\text { mandioca). } \\
\text { Terra arenosa ou } \\
\text { branca é adequada } \\
\text { para mandioca, } \\
\text { inhames, pimenta- } \\
\text { do-reino e capim. } \\
\text { Qualquer terra é boa } \\
\text { para capim. } \\
\text { Terra com piçarra }{ }^{4} \text { não } \\
\text { serve para cacau, } \\
\text { porque as raízes não } \\
\text { crescem } \\
\text { Terra dura não } \\
\text { infiltra água, o capim } \\
\text { fica degradado rapi- } \\
\text { damente. } \\
\text { Só se escolhe terra } \\
\text { para plantar cultivo } \\
\text { definitivo de ciclo } \\
\text { longo. } \\
\text { qualquer cultivo }\end{array}$ & $\begin{array}{l}\text { A área de capoeira e } \\
\text { a terra com babaçu são } \\
\text { melhores para cul- } \\
\text { tivo de milho (maior } \\
\text { produção). } \\
\text { A área de floresta alta e } \\
\text { com cipó é a melhor; dá } \\
\text { menos mato e produz } \\
\text { melhor cacau e arroz. } \\
\text { Terra boa tem as } \\
\text { espécies florestais } \\
\text { popularmente conhe- } \\
\text { cidas por maxarimbé, } \\
\text { pau preto, acapu e } \\
\text { jarana, e do arbusto } \\
\text { bananeira de seda. } \\
\text { Plantio na capoeira } \\
\text { fina dá muito mato; } \\
\text { tem que ser bem } \\
\text { queimada para di- } \\
\text { minuir a necessidade } \\
\text { de capinar. } \\
\text { Plantio de arroz pode } \\
\text { ser em capoeira com } \\
\text { mais de quatro anos de } \\
\text { descanso (pousio). } \\
\text { Quando se derruba } \\
\text { a mata e não faz } \\
\text { plantio no mesmo } \\
\text { ciclo agrícola, a terra } \\
\text { fica dura. }\end{array}$ & $\begin{array}{l}\text { Baixão próximo ao } \\
\text { curso d'água mantém } \\
\text { umidade; é indicado } \\
\text { para plantio de cacau } \\
\text { ou capim. } \\
\text { Baixão que se mantém } \\
\text { alagado é indicado } \\
\text { para plantio de capim } \\
\text { (mantém o capim } \\
\text { verde no verão). } \\
\text { O capim desen- } \\
\text { volve-se melhor e } \\
\text { degrada menos em } \\
\text { áreas planas. } \\
\text { Plantio de capim } \\
\text { em áreas enladeiradas } \\
\text { provoca erosão e } \\
\text { assoreamento dos } \\
\text { leitos dos igarapés. }\end{array}$ & $\begin{array}{l}\text { Evitar plantio de } \\
\text { cacau próximo à } \\
\text { floresta devido à } \\
\text { presença de animais } \\
\text { silvestres. } \\
\text { Plantio de pimenta- } \\
\text { do-reino somente } \\
\text { em terra nova para } \\
\text { evitar contaminação } \\
\text { por doenças. } \\
\text { Evitar plantio de } \\
\text { cacau próximo à } \\
\text { pastagem de lotes } \\
\text { vizinhos, devido ao } \\
\text { risco de fogo acidental. } \\
\text { Evitar plantio de } \\
\text { mandioca próximo } \\
\text { aos cursos d'água, } \\
\text { devido à presença de } \\
\text { capivara. }\end{array}$ \\
\hline
\end{tabular}

Fonte: Rocha (2013). 
cultivos próximos à floresta preferindose áreas pequenas de capoeira ou pasto próximas à residência e mais distantes de cursos d'água.

A preferência pela produção de arroz em áreas de floresta é justificada pelos benefícios econômicos em virtude do menor uso de mão de obra para limpeza das parcelas, pois as plantas espontâneas não dominam com a mesma intensidade. Caso não haja infestação de insetos ou ataque de animais silvestres, a produção de arroz plantado em áreas de floresta é superior àquela plantada na capoeira, $\mathrm{O}$ que para os agricultores justifica o corte da floresta, já que viabiliza maior produtividade. A Figura 2 ilustra uma queimada e plantio de arroz nas condições de produtividade acima da média regional.

Para a escolha de determinada área de capoeira, considera-se principalmente a idade da capoeira. Para alguns agricultores, uma capoeira de dois anos já é suficiente para obter boa produção de mandioca e milho, já para outros, tem que estar acima de quatro anos de pousio. $\mathrm{Na}$ avaliação dos agricultores, além da idade da vegetação, o que influencia é a qualidade da queimada que, por sua vez, impactará no tempo de trabalho a ser dedicado à limpeza das parcelas cultivadas e à produtividade física.

A degradação dos solos somente é percebida quando o processo de erosão já está avançado, como nas voçorocas e assoreamento dos leitos dos rios. Em raras situações, são percebidos outros fatores que restringem a atividade física e biológica dos solos como a compactação, erosões laminares e perda de matéria orgânica.
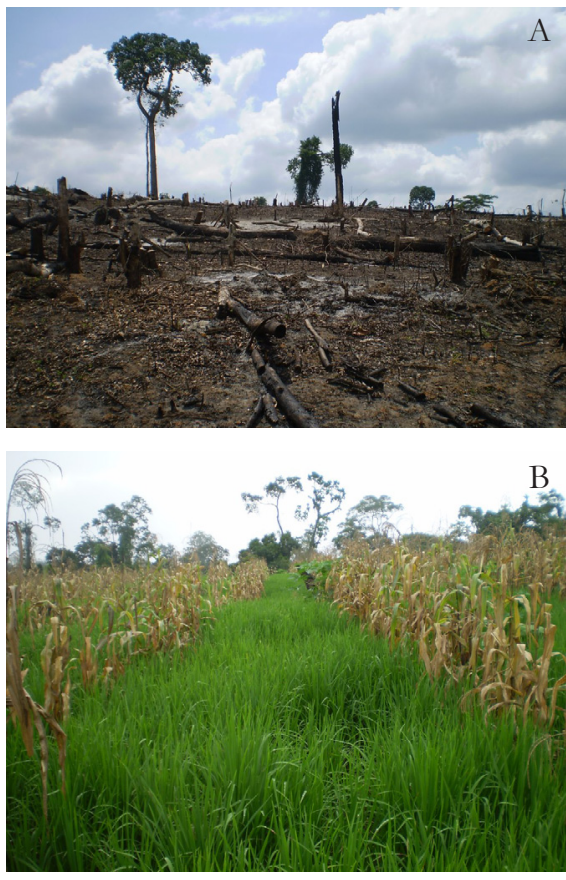

Figura 2 - A) Área queimada e plantio de arroz e B) milho em consórcio na região da Transamazônica. Fontes: Pesquisa de campo (2011) e Rocha (2013).

Pode-se postular que as famílias agem, nas condições atuais, considerando a perspectiva estratégica de uma racionalidade em relação aos meios e com a finalidade de assegurar a reprodução material. Esta lógica de ação é justificada pelos atores locais nas relações com o sistema social que pode levar a duas possibilidades de justificativa de suas diferentes práticas: a manutenção da tática de desmatamento progressivo de suas áreas de florestas ou a sua diminuição.

Entende-se que os conhecimentos e práticas estão em transformação, em um processo permanente de inter-relações entre o sistema social e natural, ou seja, em uma relação dinâmica e interdependente entre cultura e meio natural. Um 
dos aspectos do meio social que vem influenciando nas percepções e nas práticas dos agricultores advém da pressão institucional e social externa para que os mesmos incorporem novos elementos técnicos e normas externas, como a legislação ambiental, que leva a mudanças técnicas e táticas, mesmo que estas sejam temporárias (Rocha 2013).

Não se pleiteia, nesta análise, a imagem de um ator absolutamente autônomo e que persiga objetivos bem definidos, mas sim a ideia de um ator inserido em um contexto de constrangimentos e tensões, de estratégias econômicas, o qual faz parte de um sistema social que o induz a manter determinadas práticas, dependendo das condições internas e externas que podem também levar à construção de novidades organizativas, técnicas e produtivas.

\section{CONSIDERAÇÕES FINAIS}

Não são somente os conhecimentos locais dos agricultores sobre a qualidade e limitações do meio natural e sua disponibilidade, mas também, a situação familiar e sua percepção do meio socioeconômico que balizam a tomada de decisão quanto à gestão dos elementos naturais. A diversidade de percepções e conhecimentos sobre o meio natural e as diferentes visões e vínculos sociais definem as práticas dos agricultores. Apesar de a tendência predominante de transformação dos agroecossistemas em pastagens, verifica-se a diferenciação de percepções ambientais e uso de um mesmo elemento do meio natural. A degradação do meio natural é reconhecida, mas há também a crença na técnica para reversão das consequências negativas.

A compreensão da realidade socioeconômica dos agricultores, o reconhecimento dos conhecimentos envolvidos, a identificação dos objetivos familiares e percepções ambientais poderiam balizar as ações de sensibilização ambiental e a construção de alternativas técnicas e organizacionais aos atuais modelos industriais de homogeneização e modernização da agricultura, assim como amenizar as consequências do uso predatório e espoliativo do meio natural na Amazônia. Portanto, conhecer e valorizar os conhecimentos locais e incentivar o diálogo entre os saberes dos diversos atores sociais pode ser uma opção importante para entender e formular outras concepções e alterar os sistemas de produção de agricultores que seguem trajetórias produtivas que preconizam a exploração dos elementos do meio natural que ainda não incluem o objetivo de assegurar a sustentabilidade destes sistemas.

\section{NOTAS}

${ }^{1}$ Ver Reboul (1989).

${ }^{2}$ Liteira é o material que fica na superfície do solo e sob a floresta, constituído por folhas, galhos finos, flores e frutos que incorpora matéria orgânica ao solo após a decomposição.

${ }^{3}$ Juquira é a vegetação secundária proveniente de regeneração natural de diversas espécies nativas; também denominada por capoeira.

${ }^{4}$ Piçarras são concreções lateríticas de diversas formas e diâmetros, geralmente de coloração avermelhada. 


\section{REFERÊNCIAS}

Almeida, J. 2000. A Agronomia entre a teoria e a ação. Revista de Educação Agrícola Superior 18 (2):7-12.

Barrera-Bossols, N. e V. Toledo. 2005. Ethnoecology of the Yucatec Maya: simbolism, knowledge and managemente of natural resources. Journal of Latin American Geography 4(1): 9-41.

Hocdé, H. \& B. Triomphe. 2002. L'expérimentation en milieu paysan, in Memento de l'agronome. Editado por CIRAD, GRET e Ministère des Affaires étrangères, pp. 511536. Montpellier.

Leff, E. 2009. Saber ambiental: Sustentabilidade, racionalidade, complexidade, poder. Petrópolis, Rio de Janeiro: Vozes.

Reboul, C. 1989. Monsieur le capital et madame la terre: fertilité agronomique et fertilité économique. Paris: INRA.

Rocha, C.G.S. 2013. Reprodução social e práticas socioprodutivas de agricultores familiares da microrregião de Altamira, Pará, Brasil. Tese de Doutorado, Faculdade de Ciências Econômicas, Universidade Federal do Rio Grande do Sul, Brasil.

Tavares, F. B. e I. Veiga. 2006. Diversidade de saberes e práticas relacionadas à gestão das pastagens em uma localidade da fronteira agrária da Amazônia Oriental. Amazônia: Ciência e Desenvolvimento 2(3):111-126.

Toledo, V. 2005. La memoria tradicional: la importancia agroecológica de los saberes locales. LEISA - Revista de Agroecologia 20(4):16-19.

1990. La perspectiva etnoecológica: cinco reflexões acerca de las ciencias campesinas sobre la naturaleza com especial a México. Ciencias Especial 4:22-29.

Veiga, I. 2002. Savoirs locaux et organisation sociale de l'agriculture familiale amazonienne: la gestion durable des milieux en question. Tese de Doutorado,
Instituito Nacional de Pesquesa Agronômicas, Universidade de Toulouse Le Mirail, França.

Veiga, I. \& C. Albaladejo. 2002. Gestão da fertilidade dos solos de uma localidade na Amazônia Oriental: A formalização dos pontos de vista dos agricultores visando um diálogo entre agricultores e agrônomos. Agricultura Familiar, Pesquisa, Formação e Desenvolvimento 1(3): 109-137.

Recebido em 11/08/2013

Aprovado em 16/08/2013. 